\title{
Review of Anthony B. Atkinson's Measuring Poverty Around the World. Edited by John Micklewright and Andrea Brandolini. Princeton, NJ: Princeton University Press, 2019, 429 pp.
}

\section{BRIAN COLGAN}

Vrije Universiteit Amsterdam

Throughout his prolific career, the economist Anthony Atkinson was pivotal to the conceptualization and measurement of inequality and poverty. In this, his final work, published posthumously, he focusses, as he so often did, on the fundamentals of poverty. ${ }^{1}$ This is characteristic of Atkinson's "'principled' approach" to the subject and is succinctly summarized by the book's editors, John Micklewright and Andrea Brandolini, in the foreword, "there is no measurement without theory, and conversely the theoretical developments are valuable only to the extent that they are liable to being used in practice" (xix). In Measuring Poverty Around the World, Atkinson presents the theoretical underpinnings and data requirements for the measurement of global poverty before applying these lessons to sixty countries across the globe.

Before delving into the substance of the book, it is important and unfortunate to note that at the time of Anthony Atkinson's death the book was incomplete. It was only through the commendable efforts of John Micklewright and Andrea Brandolini that the book was brought to a place where it was ready for publication. Throughout the book, the editors have provided informative footnotes, indicating the gaps they have filled and, where possible, giving some insight into Atkinson's likely avenue of investigation. Despite these efforts, chapters 6-10, those addressing poverty estimates in different regions, are largely incomplete. To supplement the gaps in some chapters, two of Anthony Atkinson's long-time co-authors, François Bourguignon and Nicholas Stern, contributed afterwords on the topics of growth, inequality and poverty reduction; and poverty and climate change, respectively.

\footnotetext{
${ }^{1}$ For a discussion of Anthony Atkinson's contributions to poverty and inequality research by a host of his leading co-authors, see Aaberge et al. (2017).
} 
In the opening chapter, Atkinson asks why we should be concerned with global poverty and its measurement, and offers two sources of motivation. The first is instrumental-we care about poverty because of its relationship to other outcomes. Atkinson's example relates poverty in one country to immigration in another. He argues that relying on such motivation has disadvantages as causal relationships between poverty and other outcomes can be hard to establish. However, even where such a relationship cannot be effectively established, Atkinson continues, there should still be a moral dimension to our considerations. This is an important point, worthy of note. If we are motivated instrumentally, then global efforts to alleviate poverty in (migrant) origin countries could be reasonably pursued alongside spending on border controls in migrant receiving countries. While instrumental motivations can be useful in buttressing the value of poverty reduction, I do share the author's concern that, "if this is the sole driver of our sense of responsibility, then the degree of support is fragile and unpredictable" (11).

Instead, the author advocates that our motivation to tackle poverty should stem from intrinsic concerns. Here, he distinguishes between three positions one could take: an isolationist, a cosmopolitan, and a limited sympathy position. An isolationist position attaches zero weight to poverty outside one's own nation. A cosmopolitan position is best exemplified by the philosopher Peter Singer who essentially argues that geography should not matter morally. This is also the position taken by the World Bank when measuring global poverty: each poor individual, regardless of the geographical area they are in, is given equal weight. The limited sympathy position accords concern for individuals outside of one's own nation, but the degree of concern may dissipate along certain lines, such as geographical distance or ideological differences.

It is the limited sympathy position which is the most novel and unexplored position in the poverty literature. Atkinson suggests that this position would require nations to decide upon the weights they place on the importance of poverty in other nations, leading to each nation constructing its own measure of global poverty. Deciding on these weights would be an arduous and controversial task. However, in chapter 7, Atkinson briefly discusses poverty in Africa and the link to colonial legacy. Unfortunately, this chapter is largely incomplete, but it would have been interesting to see if Atkinson would have linked colonial legacy, and perhaps even climate change, to the position of limited sympathy. Many of the 
world's richest nations have colonial pasts and are among the largest present-day, and historic, polluters. If sympathy were linked to responsibility, then nation-specific measures of global poverty among rich countries should place a positive, perhaps greater than unity, weight on poverty in the nations that have suffered from their past actions. This approach is, from one perspective, appealing-richer nations would, in part, be held accountable for the negative externalities of their actions. Unfortunately, the effects of climate change and colonialism are so ubiquitous and international that such an approach is likely to prove too controversial at the national level. Alternatively, supranational measures of global poverty for groups of nations, such as early industrializers, could prove more feasible and may be a worthwhile undertaking.

Having established potential motivations for concern with poverty, in chapters 2 to 4 Atkinson turns to definitions of poverty, the conceptual choices which must be made and the data which is necessary for measuring poverty at both the national and the global level. These chapters are in essence an overview of the theoretical and practical fundamentals of contemporary poverty research. For those newly curious and those long familiar with the topic, these chapters provide a clear, concise and probing discussion of poverty and the choices involved in its measurement. Some of the issues here, among many others, are: the setting of poverty lines, the concept of multi-dimensional poverty, income-sharing within households, persistent poverty, and adjusting for purchasing power parity. While undoubtedly a worthy summary of these issues, for some working in this area these discussions will lack novelty. This is a consequence of Atkinson's legacy, whereby many of the suggestions and debates initiated over his career have already been implemented and are widely discussed in reports by organisations such as the World Bank. ${ }^{2}$

The remaining chapters adopt a primarily cosmopolitan view of poverty and focus on the analysis of data and estimates. Chapter 5 provides an analysis of poverty around the globe addressing such questions as: Who are the poor? What is the relationship between monetary and nonmonetary poverty measures? And to what degree do poverty estimates using the international poverty line and those using national poverty lines differ? To illustrate this point Atkinson plots the poverty rate as per the international poverty line against the poverty rate as per national poverty

\footnotetext{
${ }^{2}$ In particular, the recommendations of the Atkinson Commission on Global Poverty 2016 (World Bank 2017) have largely been adopted and incorporated into the World Bank's reporting on poverty.
} 
lines, for a number of Pacific islands-both poverty lines are intended to capture extreme poverty. In Fiji, the World Bank poverty rate is 5 percent while the Pacific Community poverty rate is 35 percent. The tension that exists between national and global measures of poverty indicates that there is scope for improvement in the measurement of global poverty.

Chapters 6 to 9 examine poverty in different regions around the world. The scope of the analysis is broad and ambitious. The author's enthusiasm for data and his knowledge of the workings of many smaller national statistics offices is infectious and inspiring. Though the text is incomplete, it is clear that Atkinson believes nations within the same region and from different regions can learn from one another in order to identify effective poverty reducing policies.

Chapter 9 focuses on measuring poverty in rich countries. In measures of global poverty, rich nations are often found to have very few individuals living in extreme poverty. This is a consequence of the low international poverty line ( $\$ 1.90$ dollars a day in $2011 \mathrm{PPP}$ ), which in practice confines poverty to poorer nations of the world. Following the efforts of Ravallion and Chen (2013), Atkinson seeks to redress this by proposing an alternative measure of global poverty. Atkinson's measure has two components: (1) for countries with mean consumption per person below a certain level, it ascribes a poverty level to the respective country equal to the international poverty line, but (2) for countries above the switching point, it ascribes a poverty level that increases by a certain percentage of the mean consumption in the respective country. The percentage increase and the switching point are related, with Atkinson's switching point occurring when 30 percent of the mean consumption per person in a country passes the international poverty line. This in essence makes poverty in richer nations relative.

The estimation of this new global poverty line unsurprisingly results in a higher rate of global poverty. However, this new approach gives equal weight to an individual living below an absolute extreme poverty line in one nation, and an individual living above this same poverty line but below a relative poverty line in another nation. Even for global cosmopolitans, this equal weight would likely prove controversial.

From a conceptual perspective, the proposed measure of global poverty may be more accurate, but it comes at the cost of blurring both the purpose of and the responsibility for global poverty. A measure of global poverty should track material progress, but in the context of extreme poverty it has also been a focal point for motivating action from individual 
nations and the international community. On Atkinson's proposed measure, it is thus not clear why relative poverty in rich nations should also motivate the international community. Furthermore, national and regional poverty lines (such as those in the EU) already set the agenda for poverty reduction in richer nations. ${ }^{3}$ The question then becomes why a new global measure of poverty, with a poverty line far below most national poverty lines in richer nations, should add value to the aim of alleviating poverty. The answer is perhaps to provide greater emphasis on the extreme tail of the income distribution in richer nations, but richer nations typically produce a number of poverty estimates using alternative poverty lines. Unfortunately, this chapter is incomplete and it is likely that Atkinson would have addressed some of these issues.

In terms of a measure of global poverty, I believe the suggestion in chapter 2 of using a dashboard of material deprivation measures is both a more salient and morally defensible approach. Inspired by the capabilities approach developed by Amartya Sen (1985), such dashboards gauge deprivation in terms of access to goods and services deemed vital by society. As Atkinson observes in chapter 3, the weakness of this approach is the value-laden choice of which dimensions to include or exclude-a choice that is not straightforward or uncontroversial.

In Measuring Poverty Around the World, Anthony Atkinson provides a valuable resource for those interested in poverty measurement. When reading this book, it is important to enjoy the lessons of one of the truly great economists of our time rather than lament the incompleteness of the analysis. While this book will not define the legacy of Anthony Atkinson, it does exemplify his wider approach to conducting research. In a rapidly changing world, with ever mounting global problems, researchers would do well to follow Atkinson's socially conscious, ethically informed, and policy relevant approach to research and problem solving.

\section{REFERENCES}

Aaberge, Rolf, François Bourguignon, Andrea Brandolini, Francisco H. G. Ferreira, Janet C. Gornick, John Hills, Markus Jäntti, et al. 2017. "Tony Atkinson and his Legacy." The Review of Income and Wealth 63 (3): 411-444.

Ravallion, Martin, and Shaohua Chen. 2013. "A Proposal for Truly Global Poverty Measures." Global Policy 4 (3): 258-265.

${ }^{3}$ For example, the Europe 2020 strategy target for poverty and social exclusion is to lift at least 20 million people out of the risk of poverty or social exclusion by 2020 compared to the year 2008 . 
Sen, Amartya. 1985. Commodities and Capabilities. Amsterdam: North-Holland.

World Bank. 2017. Monitoring Global Poverty: Report of the Commission on Global Poverty. Washington, DC: World Bank.

Brian Colgan is a $\mathrm{PhD}$ candidate and junior lecturer at the John Stuart Mill College at VU Amsterdam. His research focuses on poverty, inequality, and income mobility in Europe, with a particular emphasis on the role of parental background.

Contact e-mail: <b.p.colgan@vu.nl> 